\title{
Discussion on how to do compensation management of electric power enterprises
}

\author{
Gong Xuejun, Wang Ling \\ Benxi Power Supply Company, State Grid Liaoning Electric Power Supply Co., Ltd. \\ bxwl_650928@126.com
}

Keywords: compensation management; scientific and reasonable; role

\begin{abstract}
Compensation management is one of the core topics of human resource management of the enterprise, and an important means for the enterprise to enhance its competitiveness and attract and retain talent. Scientific and reasonable compensation management not only stimulates the enthusiasm and initiative of the staff, and promotes the staff to achieve organizational goals and improve the effectiveness of the organization, but also attracts and retains the competitive workforce of high quality, which is an important factor to promote the sustainable development of the enterprise.
\end{abstract}

Reasonable compensation system which can be described as the most important incentive method to be used most easily, is enterprises' return and appreciation to staff, so as to reward staff's effort, time, knowledge, skills, experience and creation, and enterprises' recognition of staff's contribution. In the eyes of the staff, compensation is not only their labor income, but also the representative of their value at certain degree, and the representative of the enterprise's recognition of staff, and even the representative of the ability and development prospect of staff. Scientific and reasonable compensation system is important for the development of the staff, and plays a more important role for the development of the enterprise. A reasonable compensation system plays an important role beyond measure in promoting the management efficiency of enterprises.

\section{The important role of compensation management}

Compensation management is an important factor to promote the sustainable development of enterprises

Talent is the key for enterprises having a share in the fierce market competition. The construction of a good compensation system is the normalized way to retain the talent of the enterprise. In the new era when modern enterprise management regards people as the center, human resources become the crucial assets of the enterprise. The reasonable unification of retaining key talent, stimulating the potential of the talent, and realizing the individual and organizational objectives becomes the key to win the future sustainable development of the enterprise, while in this regard, the compensation plays a basic role. Every enterprise needs a competitive compensation to attract talent, as well as a certain guaranteed compensation to retain talent. Appropriate compensation management strategy is able to form a unified situation in the enterprise, making the enterprise attract and retain talent, then enhance the competitive advantage and achieve sustainable development of the enterprise.

Compensation management is a powerful tool for the realization of enterprise strategic objectives.

If the enterprise strategy is regarded as the lifeline of enterprise survival and development, human resource management is an important chain of enterprise strategy. Among them, the contribution of the compensation management to the enterprise human resources strategy is obvious. As an important part of enterprise strategy, compensation management can create and change the internal and external environment through its function to the employee, work team and the overall enterprise, so as to effectively promote the realization of enterprise strategic objectives. 
First of all, there is an internal relation between the enterprise's compensation policies, compensation system and the major organizational changes. According to statistics, $50 \%-70 \%$ of the plans of the enterprise process reengineering efforts have failed to achieve the desired goal, and the one of the important reasons is the lack of consistency between the reconstructed process and the enterprise's compensation system. Secondly, if compensation, as a powerful tool of motivation and communication, can be used effectively, it can play a role of communication and strengthening new values and behaviors and it can be the importance tool of providing compensation while achieving new performance goals. In this way, the compensation will be conducive to strengthening the acceptance and recognition of the changes, so as to pave the way for the realization of the strategic objectives of the enterprise.

The compensation management plays an increasingly important role in human resource management in the new situation.

Human resource management has such functions as human resources planning, or regional allocation, employee development, employee support and the protection of rights and interests, and these functions and salaries are closely related, mutually influenced and promoted and inseparable, together forming a complete human resource management system. Compensation management is an important part of human resource management system as well as the organization operation and transformation and it, together with other human resource management functions, forms a platform where the organizational vision and overall strategic objectives can be realized.

\section{The problems existed in the compensation system of the old system}

1) The employees' attitude to labor is backward, the thought of recompensing according to the amount of labor expended is deeply rooted and the egalitarianism prevails. The thought of rewards according to the performance and the ability is not dominant in people's concept of compensation.

2) There is no systematic performance management system, of which the non-marketization leads to the big difference between enterprise overall compensation levels, and there is no performance measurement standards or fair outer environment of the new capital, leading to the loss of staff morale and key talent and the precipitation of large amount of low efficient employees.

3) The setting of enterprise compensation level applies the administrative level, without conforming to the relative importance of the position in the enterprise, or the job performance of the staff, so the differences of the positions are weakened, the importance of key positions is not highlighted, and the equal compensation of different works appears, causing internal injustice.

4) The design and implementation of enterprise compensation do not realize the marketization and follow the pattern of the planned system, where the compensation of people at all levels is relative to the administrative levels, which blocks various types of talent transferring to the most needed positions, and qualifications, rather than abilities, become an important standard of talent and compensation level has no direct contact with the individual's job performance.

\section{The key issues in need of solving in the compensation system}

Only when staff gets reasonable compensation, their most original physiological needs are met, and they get effective incentive, and will join the enterprise administrators to achieve the organizational goals. When the staff's work is fully integrated into the enterprise development goals, the enterprise administrators will be fully supported, so as to form a good corporate atmosphere and achieve the enterprise development strategy.

\section{The main characteristics of the compensation management}

The income of Chinese professional managers will become more and more standardized.

The "annual compensation system" of professional managers is the operator's compensation system in the periodic unit of year, to determine the operator's basic income, and the risk income is paid according to the fluctuation of operating result. This form of distribution, to a certain extent, 
links the income of the operators to the value of the state-owned assets, the size of the enterprise and the responsibility and the risk associated with operating, and separates it with the income distribution of employees. It fully highlights the operator's position and affirms the special and complex labor of employees. However, many problems still exist in the annual compensation system after its many years of implementation. For example, the evaluation method of the operator's performance is not perfect, the calculation of annual compensation is complex, the evaluation index is cumbersome, and the evaluation lacks of scientificity and reality. The "annual compensation system" is mainly in the form of currency and the position consumption is disordered, which is easy to sharpen the contradiction inside the enterprise, and the cadre personnel system does not match with the operator and labor market. After China's entering WTO, the number of foreign companies in China increases, which will be in favor of the formation of the professional managers market and the standardization of professional managers' income.

In order to retain talent, not only the enterprise should provide the staff with the competitive salary, but also generous benefits is essential

Since its establishment, the China State Grid Corp, with its generous benefits, has attracted, trained and retained a large number of talent, established a first-class staff team, and created a healthy large family with inside competiveness. It has designed unique welfare policies, to build its own competitive advantage, and introduced diversified welfare projects, to provide staff with a fine environment of self - development and self - realization.

\section{The content of modern compensation management}

The compensation management and performance appraisal management are inseparable

The success of any outstanding compensation management must be cooperated with scientific and effective assessment system and assessment method.

The compensation structure should change with the industry and the enterprise

As a part of the choices of compensation strategy, the compensation structure is becoming an important part of the compensation management. Compensation structure mainly refers to the proportion of wages, bonuses, allowances, equity, benefits, and the proportion of regular wages and irregular wages (performance wages). These proportions, like the regulator valve, integrate and generate many new compensation patterns.

The compensation management should complement the enterprise culture and the enterprise image construction

Compensation management is the internal material engine of the enterprise, while enterprise culture construction is the internal spirit engine. A generous compensation can attract and retain outstanding talent, and excellent enterprise culture and the excellent enterprise image can arouse a high degree of enthusiasm and creativity, and even attract and retain the top talent and make them work actively by medium competitive compensation.

The process of compensation management encourages and emphasizes fair competition

The essence of compensation management is to improve the labor productivity, and the lever to improve labor productivity is competition. If a compensation policy encourages and creates a fair competition, this compensation management is full of energy. In order to achieve this goal, it must be stressed that compensation should combine with the fair and scientific assessment system, contributions, and individual, team and organizational performance and the compensation gap should be properly widened, to show the obvious function of "awarding the diligent and the superior and punishing the idle and the inferior".

In short, the scientific compensation management is the source of enhancing cohesion and attraction of the enterprise, as well as an important way to achieve the people-oriented management. If there is no good compensation management, human resource management is impossible due to the lack of bearing of real significance; on the contrary, effective compensation management will make many problems of human resource management to be solved easily. Nowadays when the people-oriented management is emphasized, enterprises pay more and more attention to human 
factors, and compensation management will play an increasingly important role in improving people's status, stimulating their energy, and developing their life quality.

\section{Reference}

[1] Ding Yuelan, Han Lei. Review of competency compensation management based on competency [J]. Science and Management, 2009, (03).

[2] Zhao Hai. Compensation management and human nature hypothesis [J]. Economist, 2010, (10).

[3] Yang Lan. The application of the two-factor theory in the compensation management [J]. China Commerce and Trade, 2010, (19).

[4] Chang Jianqiang. Discussion on the compensation management [J]. Modern Business, 2010, (17).

[5] Han Yi, Li Tao. Study and analysis of the frontier fields of compensation management [J]. Industry and Technology Forum, 2011, (13). 